\title{
ВЫЯВЛЕНИЕ ИНДИКАТОРОВ СОЦИАЛЬНО-ЭКОНОМИЧЕСКОГО РАЗВИТИЯ МУНИЦИПАЛЬНЫХ ОБРАЗОВАНИЙ
}

\section{IDENTIFICATION OF INDICATORS OF SOCIO-ECONOMIC DEVELOPMENT OF MUNICIPALITIES}

\section{T. Kurbatskaya}

A. Sukhareva

Summary: This article considers the issue of identifying indicators of socio-economic development of municipalities, which allow us to give a qualitative assessment of the state and dynamics of the main indicators of socio-economic development of the territory.

Keywords: indicator of socio-economic development, municipal formation, socio-economic development.

\author{
Курбацкая Татьяна Борисовна \\ к.nсх.н., дочент, Российская открытая академия \\ транспорта (МИИТ) \\ alterego123@yandex.ru \\ Сухарева Анна Дмитриевна \\ Российская открытая академия транспорта (МИИТ) \\ an.sukhareva2018@yandex.ru
}

Аннотация: В рамках данной статьи рассматривается вопрос о выявлении индикаторов социально-экономического развития муниципальных образований, которые позволяют дать качественную оценку состояния и динамики основных показателей социально-экономического развития территории.

Ключевые слова: индикатор социально-экономического развития, муниципальное образование, социально-экономическое развитие.

рии.

В свою очередь индикаторы должны отражать наиболее широкий спектр осуществляемых муниципальным образованием процессов. Внедрение в работу муниципальных образований Digital technology позволит быстро получать результаты, соответствующие данному конкретному периоду времени. Следует понимать, что система индикаторов должна быть гибкой и понятной, они должны отражать реальную действительность. Основным требованием при комплектации системы индикаторов является сопоставимость показателей во временных рамках. Необходимо учесть, что общедоступность информации о социально-экономическом развитии муниципального образования является одним из важнейших условий привлечения инвесторов, а также действенного использования муниципальных ресурсов. Кроме того, следует учесть, что индикаторы - это не только показатели социально-экономического совершенствования муниципального образования. В ы явление индикаторов социально-экономического развития муниципального образования является сложным процессом, так как их правильный выбор индикаторов позволяет определить, насколько объективными будут выводы относительно коррекции социально-экономического развития муниципального образования [2, с. 27]. Доминирующей целью при комплектации системы индикаторов является создание системы обработки полученных количественных и качественных характеристик данных индикаторов, которые могут точно оценивать поставленные цели и задачи. 
В ходе исследований были выявлены разрозненные индикаторы социально-экономического развития муниципального образования, которые объединены нами в 3 группы одной системы. К социальным индикаторам относятся:

1. Уровень жизни населения:

- доходы населения (совокупность всех материальных средств);

- отток населения (переезд в крупные города);

- сохранение достопримечательностей города;

- социальная поддержка многодетных семей, инвалидов и ветеранов ВОВ;

- обеспеченность спонсорской помощью (благотворительность).

2. Здравоохранение:

- нехватка больничных коек;

- расширение медицинских услуг;

- обеспеченность населения высококвалифицированной медицинской помощью;

- повышение уровня предоставления неотложной скорой помощи;

- качество оказываемых медицинских услуг.

3. Образование:

- обеспеченность детей дошкольного возраста местами в детских дошкольных учреждениях;

- потребность в постройке новых средних образовательных учреждений;

- повышение качества образования (привлечение молодых и квалифицированных педагогов, внедрение инновационных технологий);

- создание групп продленного дня и школьных лагерей;

- расширение сферы дополнительного образования (культура, спорт).

К экономическим индикаторам относятся:

1. Управление муниципальными финансами в муниципальном образовании:

- проблема формирования городского бюджета (нехватка средств для осуществления программ);

- повышение налоговых поступлений в бюджет от туризма и связанных с ним предприятий сферы обслуживания и малого бизнеса (так как в основном все налоговые поступления от малых предприятий по закону Владимирской области идут непосредственно в местные бюджеты);

- повышение занятости населения (создание новых рабочих мест для молодежи и создание возможностей для трудоустройства пенсионеров);

- прирост количества субъектов малого и среднего предпринимательства, осуществляющих деятельность на территории муниципального образования [4];

- привлечение предприятий/инвесторов.
2. Жилой фонд:

- обеспеченность жильем;

- переселение из ветхого жилья в новый жилой фонд (улучшение жилищных условий);

- стоимость жилищно-коммунальных услуг;

- благоустройство жилищного фонда (наличие центрального отопления, водопровода, горячего водоснабжения, канализации, газоснабжения, качество жилья);

- программа помощи многодетным семьям.

3. Благоустройство города:

- капитальный ремонт многоквартирных домов;

- обеспечение по содержанию и уборке мест захоронения (своевременная и систематическая уборка территории кладбища: дорожек общего пользования, оград, малых архитектурных форм, проходов и других участков хозяйственного назначения (кроме могил);

- обеспеченность города в новых очистных сооружениях (возможность выделения площади земли под очистные сооружения, удаленности этой площади от жилья, топографии местности, грунтовых, гидрологических и климатических условий, характера и места расположения водоема, в который могут быть спущены очищенные воды);

- ремонт автомобильных дорог (комплекс работ по воспроизводству ее первоначальных транспортно-эксплуатационных характеристик, при котором производится возмещение износа покрытия, восстановление и улучшение его ровности и сцепных качеств, устранение всех деформаций и повреждений дорожного покрытия, земляного полотна, дорожных сооружений, элементов обстановки и обустройства дороги, организации и обеспечения безопасности движения);

- благоустройство скверов и парков; строительство детских площадок. Целью формирования групп индикаторов является дальнейшее исследование доминантности их выраженности, на основании чего планируется:

1) разработка программ социально-экономического развития муниципального образования;

2) определение «точек роста» социально-экономического развития муниципального образования;

3) определение критических точек социальноэкономического развития муниципального образования;

4) возможность динамического и сравнительного анализа социально-экономического развития данного муниципального образования и других $\mathrm{MO}$;

5) возможность разработки механизма контроля деятельности администрации муниципального образования. 
В процессе выявления индикаторов социально-экономического развития муниципальных образований была использована методика ранжирования Т.Б. Курбацкой [5].

Таким образом, создание системы индикаторов со- циально-экономического развития муниципального образования будет способствовать выявлению доминирующих целей и задач социально-экономического развития муниципального образования, что может оказать кардинальное воздействие на усовершенствование менеджмента муниципального образования.

\section{ЛИТЕРАТУРА}

1. Бондаренко Н.А., Сюпова М.С. Организация проведения мониторинга реализации стратегии социально-экономического развития муниципального образования // Вестник ТОГУ. - 2016. - №4(43). - 160 с.

2. Закиров 3.И. Социально - экономическое развитие муниципального образования [Текст] / 3.И. Закирова // «Экономика и социум» — №5 (48) - 2018. 1925 c.

3. Официальный сайт Федеральной службой государственной статистики [Электронный ресурc] - URL: https://rosstat.gov.ru/

4. Официальный сайт администрации г. Покров - Муниципальное образование «Город Покров» [Электронный ресурc] - URL: https://pokrovcity.ru/

5. Мотивационная структура профессиональных намерений в процессе оптации и профессиональной подготовки в ВУзе [Электронный ресурс] - https:// www.dissercat.com

( Курбацкая Татьяна Борисовна (alterego123@yandex.ru), Сухарева Анна Дмитриевна (an.sukhareva2018@yandex.ru).

Журнал «Современная наука: актуальные проблемы теории и практики»

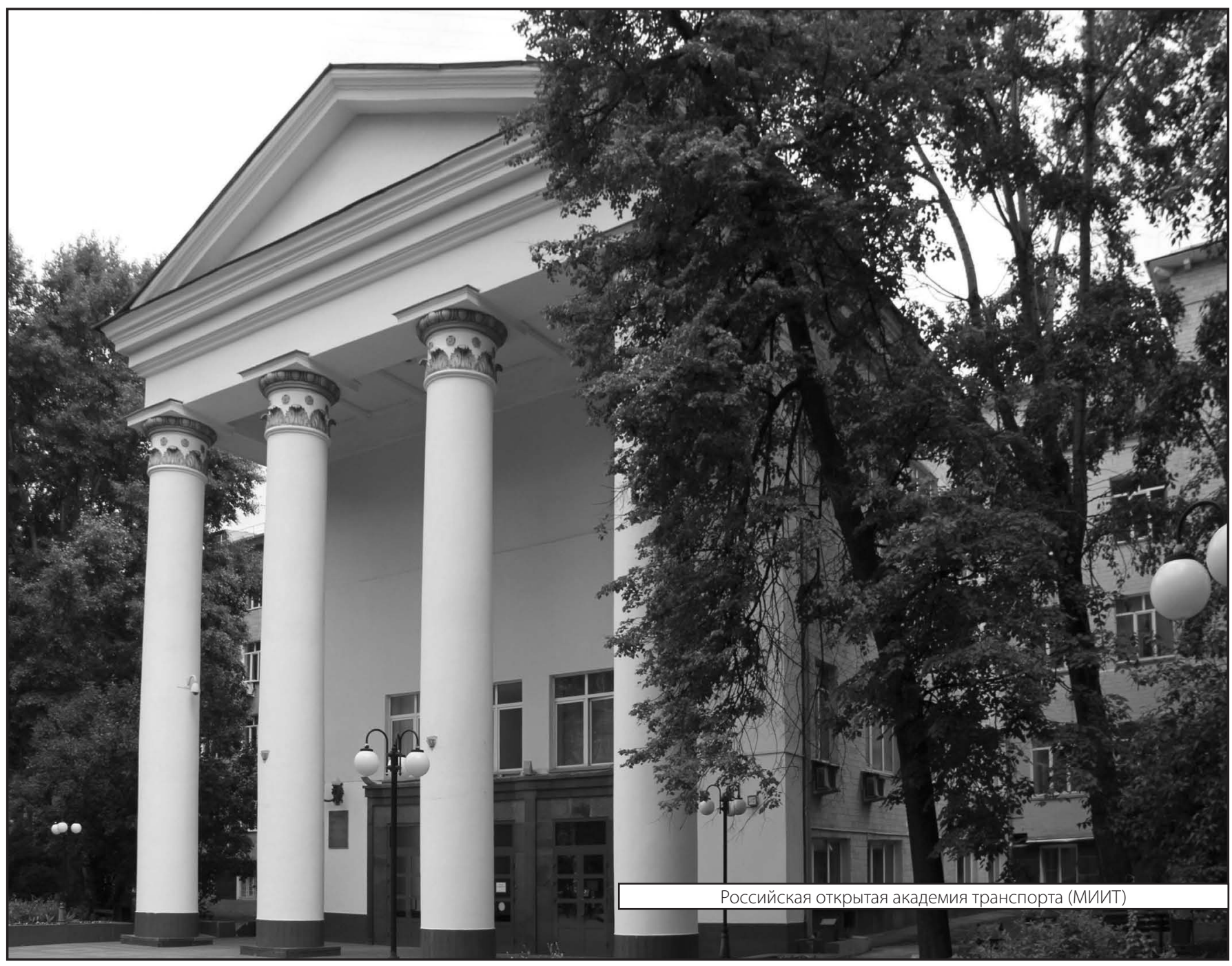

